\title{
The Place of the Social Sciences in Human Knowledge*
}

$\mathrm{T}^{\mathrm{H}}$ E condition of economics and other social sciences to-day presents a paradox. More and more students each year come to study the social sciences in universities. But there is not a corresponding recognition, either by men of affairs or by men of science in other fields, of the authority of those who teach these subjects.

For this there is one reason, for which workers in social sciences are not responsible; this is the common failure both of the general public and of other scientific workers to understand the nature of economic problems and the distinctions, say, between economics and engineering, or sociology and biology. The engineer or any other technician considers alternative means of meeting a given need. The economist describes and explains the behaviour of mankind in the use of scarce resources. Their spheres are different, and engineering skill is no guide in the solution of economic problems. So mice are not men, and to argue direct from mice, or from fruit-flies, to human society is to court disaster.

There are, however, other reasons for the unsatisfactory status of the social sciences, for which workers in the social sciences do appear to be responsible. There are two reasons in particular. The first reason is the frequent failure of social scientists to be scientific in method : in particular, their neglect of observation of facts, as the basis of theories and as the control of theories. This failure is illustrated by the debate among professional economists, as to the causes and nature of unemployment, that has followed on the publication of J. M. Keynes' "General Theory of Employment". The distinguishing mark of economic science as illustrated by this debate is disregard for the need of verification of theories by observation of facts, even when the theories are theories about the real world and not about abstractions. Economics so pursued cannot claim to be a science. William Harvey founded modern psychology by professing "to study and to teach anatomy, not from books, but from dissections; not from the positions of philosophers, but from the fabric of nature". Economics and other social sciences are still excessively occupied with argument from "the positions of philosophers", though they profess to deal with phenomena.

The established natural sciences may be compared to the visible colours of the spectrum from red to violet; they are spread out in a continuous band of changing character, from the abstraction of mathematics through physics and chemistry to the complexity and lesser certainty of biology. But as sunlight contains rays necessary to health beyond the visible spectrum, so human knowledge is not complete without an extension beyond the recognized natural sciences. In this analogy, economics and the other social sciences are not infra-mathematics, but ultra-biology.

The second reason is the failure of some economists and political scientists to be scientific, in detachment from partisan action and in avoidance of giving

* Summary of a farewell address delivered by Sir William Beveridge at the London School of Economics and Political Science on June 24. judgment continually on controversial practical issues. The business of the social scientist is to study and compare different types of economic, political and social organization, as the biologist studies forms of life or the chemist compares the reactions of different materials under various conditions. The biologist does not hate rabbits, and love frogs. The chemist, as a preliminary to an impartial comparison of the properties, say, of leather and of rubber and their respective advantages for different purposes, does not join the directorate of a tannery. Yet this is just what the economist or political scientist does who becomes an avowed partisan, whatever his party. The service of social science and the practice of the arts of democratic government are vocations each of which may be pursued with sincerity and singleness of purpose, but they cannot be combined. A social scientist cannot become a politician by speech or writing or affiliation without losing value as a scientific investigator and a teacher. Without derogation from essential academic freedom, those who choose the academic vocation in the social sciences should impose on themselves reticences and self-denials in the political and practical field, which would not be necessary for teachers of other subjects, but are necessary to give to the social scientist that emotional detachment from his subject which eomes naturally to the biologist or chemist.

The place of the social sciences in human knowledge is that of the last-born of the sciences of observation; their affinities are here, rather than with mathematics or philosophy or arts. As lastborn, they are in their infancy; moreover, their complexity and the lack of precise information makes them slow of growth. Adam Smith (publishing the "Wealth of Nations" in 1776) corresponds in economics to Copernicus in astronomy (circulating his theory in a tract of 1529). To-day, 150 years after Adam Smith, economics could not hope to have travelled as far as astronomy reached in 150 years from Copernicus, that is, to Newton. Economists should be content if they are now as far as Tycho Brahe and they may be encouraged by his achievement. Tycho's theory, that the planets went round the sun and that the sun went round the earth, was wrong: his numerous observations, made with integrity and industry, became the basis of Kepler's discovery of the truth. To be wrong in our theory matters relatively little, if we are honest and industrious in our observations.

Modesty about the present achievements of social science should involve no discouragement; nor should there be modesty in our ambitions. Without better understanding by man of his own nature and that of human society, civilization is in danger. For the good of mankind, the social sciences have still to win for themselves laboriously the recognition and assured place of influence already won by the natural sciences. The two keys that can unlock for them the gateway of their promised land-both keys must be used-are observation and detachment. 